\title{
A Rare Cause of Acute Abdominal Pain in Childhood: Peptic Ulcer Perforation
}

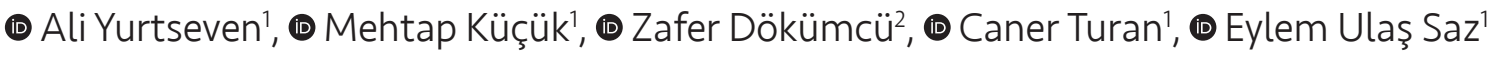 \\ 'Ege University Faculty of Medicine, Department of Pediatrics, Division of Emergency Medicine, İzmir, Turkey \\ ${ }^{2}$ Ege University Faculty of Medicine, Department of Pediatric Surgery, İzmir, Turkey
}

\begin{abstract}
Four children with a mean age of 12 years were referred to our emergency department with a history of abdominal pain. Examination revealed tenderness in the lower abdomen, in particular the left iliac fossa. The youngest child, who was 3 years old, also presented with shock. Abdominal $\mathrm{X}$-rays revealed free air under both hemidiaphragms. Subsequent surgery was administered as the primary treatment of three patients and a partial resection was performed in the remaining one. The youngest child died and the others were discharged. These cases emphasize that although uncommon, alternate diagnoses must be kept in mind in children presenting with lower abdominal pain.

Keywords: Child, intestinal perforation, abdominal pain
\end{abstract}

\section{Introduction}

Peptic ulcer disease (PUD), which may be complicated by severe hemorrhage or perforation, is a rare cause of lifethreatening abdominal pain in children. Perforation is the second most common complication of PUD following acute gastrointestinal hemorrhage $(1,2)$. The disease is characterized by a loss of tissue penetrating gastrointestinal mucosa. Although the exact etiology of peptic ulcer perforation still remains unclear, some factors such as stress, an underlying disease or corticosteroid/non-steroidal anti-inflammatory drugs are proven to play a role $(2,3)$. Peptic ulcers are often localized in the anterior wall of the duodenum. The gold standard of diagnosis is endoscopy. In case of perforation, there is a free air under the diaphragm diagnostic and another radiologic examination is not required $(3,4)$. However, an absence of free air under the diaphragm does not rule out the diagnosis of perforation (4). The aim of this case series is to emphasize that gastrointestinal perforation should be considered in the differential diagnosis in children (especially adolescents) presenting with acute abdominal pain even in the absence of dyspeptic symptoms. Four children (2 girls, 2 boys) with a mean age of 12 years (3-16 years) who presented with peptic ulcer perforation (PUP) were included in this study. Three had perforated duodenales and one had a perforated gastric ulcer. The characteristics of the patients are presented in Table I. Informed consent was given by all parties involved.

\section{Case Reports}

\section{Case 1}

A 16 years-old boy presented to the emergency department with a history of intermittent pre-prandial epigastric pain over a 3-month period. Cholelithiasis was detected in his prior examination at another healthcare facility. Upon admission, 


\begin{tabular}{|c|c|c|c|c|}
\hline Age & 16 & 3 & 13 & 16 \\
\hline Gender & Male & Female & Female & Male \\
\hline Presentig symptom & Abdominal pain & Abdominal pain, fever, vomiting & $\begin{array}{l}\text { Abdominal pain, } \\
\text { abdominal distension and } \\
\text { vomiting }\end{array}$ & Abdominal pain \\
\hline $\begin{array}{l}\text { Duration of } \\
\text { symptoms }\end{array}$ & 3 months/ 1 hour & 10 days & 4 days & 8 days \\
\hline Family history & Negative & Negative & $\begin{array}{l}\text { Father-duodenal ulcer } \\
\text { perforation }\end{array}$ & Negative \\
\hline Physical examination & Epigastric voluntary defense & $\begin{array}{l}\text { Ill appearance, abdominal distension and } \\
\text { peritoneal signs }\end{array}$ & $\begin{array}{l}\text { Diffuse tenderness and } \\
\text { rigidity }\end{array}$ & $\begin{array}{l}\text { Diffuse tenderness and } \\
\text { rigidity }\end{array}$ \\
\hline WBC & $23800 / \mathrm{mm}^{3}$ & $3470 / \mathrm{mm}^{3}$ & $19500 / \mathrm{mm}^{3}$ & $19500 / \mathrm{mm}^{3}$ \\
\hline CRP & Negative & Negative & $16.44 \mathrm{mg} / \mathrm{dL}$ & $2.5 \mathrm{mg} / \mathrm{dL}$ \\
\hline X-ray & $\begin{array}{l}\text { Bilateral subdiaphragmatic } \\
\text { free air }\end{array}$ & Not performed & Multiple air-fluid levels & Not performed \\
\hline CT scan & Not performed & Not performed & Not performed & $\begin{array}{l}\text { Free air in the } \\
\text { abdominal cavity }\end{array}$ \\
\hline Localization of ulcer & Duo denum anterior wall & Greater curvature of stomach & Duodenum & $\begin{array}{l}\text { Duodenum anterior } \\
\text { wall }\end{array}$ \\
\hline Treatment & $\begin{array}{l}\text { Primary suture, } \\
\text { omental patch }\end{array}$ & Partialre section of stomach & Primary closure & $\begin{array}{l}\text { Primary suture and } \\
\text { omental patch }\end{array}$ \\
\hline Histology & Acute benign ulcer & Acute gastric ulcer and perforation & Chronic gastritis & Ulcer repair tissue \\
\hline Oral feeding & $3^{\text {rd }}$ day & - & $7^{\text {th }}$ day & $4^{\text {th }}$ day \\
\hline Hospital stay & 6 days & - & 13 days & 7 days \\
\hline
\end{tabular}

his physical examination revealed that there was rigidity in his epigastrium. Laboratory tests revealed an elevated white blood count $\left(23.800 / \mathrm{mm}^{3}\right)$ and neutrophil predominance $\left(21.900 / \mathrm{mm}^{3}\right)$. Bilateral sub-diaphragmatic free air was seen on X-ray (Figure 1). Abdominal ultrasonography was normal except for cholelithiasis. Urgent surgical exploration revealed an area of perforation on the duodenum anterior wall (3.4 $\mathrm{mm}$ ) and a surrounding indurated, edematous and fragile area. Primary repair was performed with an omental patch. Oral feeding was commenced on the third day postoperative. The patient was given antiulcer therapy with anti-biotherapy and subsequently discharged.

\section{Case 2}

A 3-years-old girl, who had been on antibiotics for a urinary tract infection for 10 days, presented with abdominal pain, fever and vomiting. On physical examination, she had an ill appearance and her clinical picture was suggestive of hypovolemic shock. She had abdominal distension and peritoneal signs. Routine blood tests were normal except for leukopenia $\left(3470 / \mathrm{mm}^{3}\right)$ and moderately high levels of amylase (178 IU/L), hyponatremia (123 mEq/L) and hypocalcemia (6.6 $\mathrm{mg} / \mathrm{dL}$ ). She was operated on urgently after fluid resuscitation.

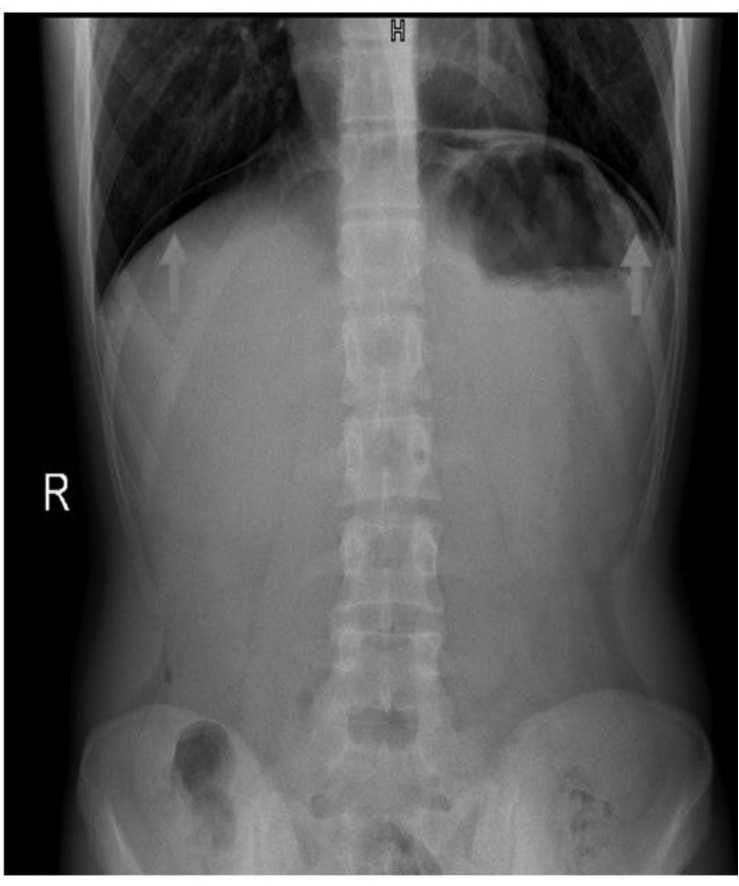

Figure 1. Arrows: bilateral sub-diaphragmatic free air on X-ray 
The area of perforation on the greater curvature was resected and primarily repaired. On day 5 postoperative, she died in intensive care unit due to brain death with severe brain edema on computed tomography (CT) scan and no sign of cranial perfusion on scintigraphy. A histological evaluation confirmed an acute gastric ulcer and perforation.

\section{Case 3}

A 13-year- old girl had suffered from abdominal pain, abdominal distension and bilious vomiting for 4 days. A CT scan was obtained that showed left lower lobe pneumonia and ileus in another center. On physical examination, there were diffuse tenderness and rigidity on the abdomen. Multiple air-fluid levels and dilated bowel loops were seen on X-ray scanning (Figure 2). Laboratory tests revealed leukocytosis, elevated C-reactive protein (CRP) and aspartate aminotransferase (AST) levels whereas other biochemical values were within normal limits. The patient underwent emergency surgery. Bile and purulent fluid was aspirated, adhesiolysis of the bowel loops and primary repair of the duodenal perforation were performed. Antibiotherapy and gastroprotective medication were used during postoperative follow-up.

\section{Case 4}

A-16-years old boy who had previously taken anticonstipation therapy elsewhere presented with abdominal pain for 8 days. His past medical history revealed that he had had an appendectomy. Diffuse tenderness and rigidity were noticed on abdominal examination and leukocytosis and an elevated CRP level necessitated a CT scan which showed free air in the abdominal cavity (Figure 3). Urgent exploration revealed an area of perforation on the duodenum anterior wall that was repaired with primary suture and an omental patch. Antibiotherapy and gastroprotective medication were used during the postoperative follow-up.

\section{Discussion}

PUD is rare in children. Therefore, it may be missed or only diagnosed upon the presentation of complications such

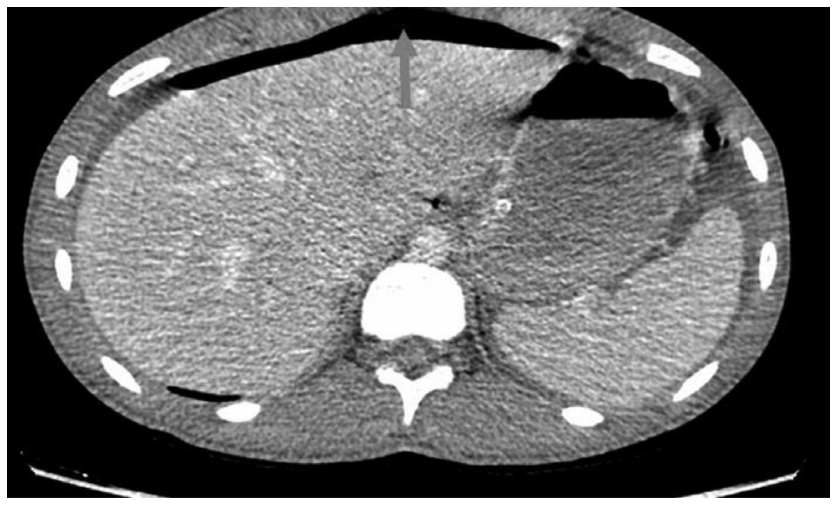

Figure 2. Computed tomography scan showed free air before operation as hemorrhage or perforation. Modern effective medical therapy has reduced the incidence of PUD and the need for surgical treatment (4). Nevertheless, due to complications of the disease, there is still a significant morbidity and mortality rate. Especially in adolescents, as a rare cause of abdominal pain, PUP should be considered in the differential diagnosis. PUD usually occurs in adulthood. However, it has also been reported in children (3-5). Most peptic ulcers in children occur between the ages of 8 and 17 years (mean 12 years) (3). Also, PUP is more common in adolescents than in other age groups and also is more common in males. Hua et al. (3) previously reported a significant predominance of adolescents (90.4\%) and males (80.7\%). However, in our study, gender distribution was equal in our limited number of patients. If we exclude the youngest patients from our series we can also conclude that there is a male predominance in adolescents. Patients are usually referred to the emergency department with acute abdominal pain and peritoneal signs are seen on physical examination. Perforation of the anterior surface of the stomach leads to the first sign which is often sudden, intense abdominal pain. Posterior wall perforation leads to tenderness and guarding, which often radiates pain to the back. Schwartz at al. (6) reported a patient with PUP, who presented to an emergency department with acute abdominal and shoulder pain. In our study, acute abdominal pain (mean 5.75 days) and peritoneal signs were observed as the most common findings. We noted that $50 \%$ of patients had vomiting and one patient had fever. There were three patients with diffuse peritoneal signs and one of our patients had localized defense. A study by Lee et al. (7) reported differently on a 30-month-old case who presented with acute massive hematochezia. A clinical study in 73 children showed that younger patients especially presented with vomiting, older patients mostly presented with pain which was similar to our study (2). Case 2 had vomiting and cases 1 and 4 had pain while case 2 had both of these symptoms. In research from Shangai, it shows that a family history of peptic ulcer is a very strong risk factor in PUD [odds ratio

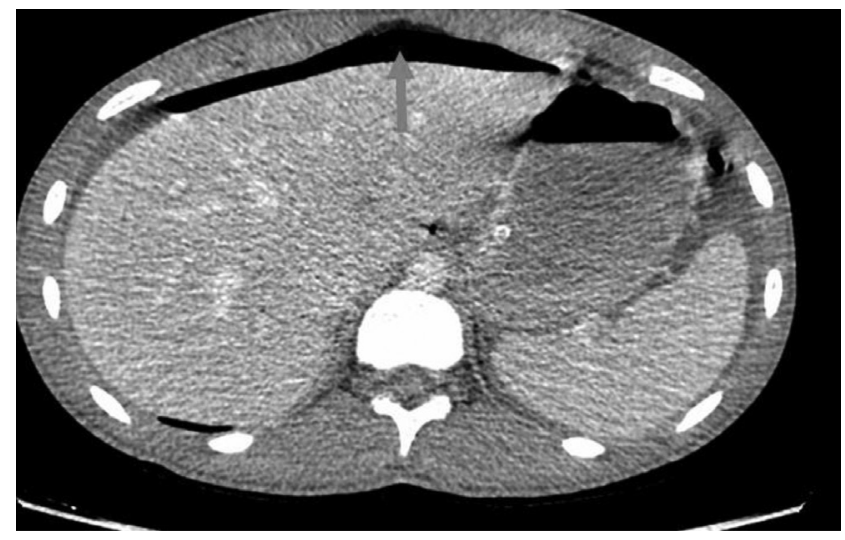

Figure 3. Computed tomography scan showed free air before operation 
$(\mathrm{OR})=4.94,95 \%$ confidence interval $(\mathrm{Cl})=3.69-6.61]$ (8). In the development of duodenal ulcers, García-González et al. (9) made a report that the carriage of the IL-1B-511*C/IL-1B$31^{*} \mathrm{~T} / \mathrm{IL}-1 \mathrm{~B}+3954^{*} \mathrm{C} / \mathrm{IL}-1 \mathrm{RN}{ }^{*} 2$ allele combination in addition to bacterial and environmental factors play a key role in the development of duodenal ulcers. One of our patients has a positive family history. In a study from Philadelphia, leukocytosis was evaluated in patients who applied after 24 hours in five of seven cases and in one of four patients applied within 24 hours (10). In our study 3 patients who presented in the acute period had leukocytosis, but case 2 who presented at day 10 had leukopenia. Even though extra luminal free air is the most common and consistent finding of gastroduodenal perforation, it may be absent at the onset of symptoms as was shown in $30 \%-50 \%$ of patients (11). Perforation sites can be often categorized by the CT findings, for instance: ulceration or a focal defect of the gastroduodenal wall, air bubbles in contact with the stomach or the duodenum, abrupt wall thickening associated with adjacent "dirty fat" density and local fluid between the duodenum and the pancreatic head (12). One of our patients had extraluminal free air on X-ray, one on CT, which confirms that absence of free air in imaging studies does not exclude gastrointestinal perforation. Duodenal ulcers were approximately 20-30 times more prevalent than gastric ulcers $(2,3)$. In a recent study from Poland, duodenal ulcer perforations were more common (13). We noted 3 cases of duodenal ulcer and one of gastric ulcer. Surgical options range from localized ones (ie, bleeding, perforation or obstruction) to definitive ulcer operations. Definitive ulcer surgeries (eg, highlyselective vagotomy, truncal vagotomy with gastric drainage or partial gastrectomy) aim to reduce acid secretion and hence decrease the ulcer recurrence rate (2-4). Since these procedures include operative time and can be associated with increased perioperative morbidity and long-term adverse physiologic sequelae, in our cases, localized therapy was performed. Dakubo et al. (14) conducted a retrospective and prospective hospital-based study in Chana. In their study, simple closure with an omental patch at a rate of $94.3 \%$, truncal vagotomy and drainage with a rate of $3.2 \%$ and Billroth II partial gastrectomy with a rate of $2.2 \%$ were performed. Laparoscopic repairs were also reported (15) but open surgery still remains the approach of choice in the majority of centers for these patients. Omental patch is a preferred method to minimize the risk of leakage. PUP should be suspected in adolescents who suddenly develop severe, diffuse abdominal pain. We also conclude that although PUP is rare during childhood, it is a life-threatening condition.

\section{Ethics}

Informed Consent: The verbal consent was taken from the patient's parents.

Peer-review: Externally peer-reviewed.

\section{Authorship Contributions}

Surgical and Medical Practices: A.Y., Z.D., E.U.S., Concept: A.Y., M.K., E.U.S., Design: A.Y., C.T., E.U.S., Data Collection or Processing: M.K., C.T., Analysis or Interpretation: A.Y., Z.D., E.U.S., Literature Search: A.Y., C.T., M.K., Writing: A.Y., Z.D., E.U.S.

Conflict of Interest: No conflict of interest was declared by the authors.

Financial Disclosure: The authors declared that this study received no financial support.

\section{References}

1. Tam YH, Lee KH, To KF, Chan KW, Cheung ST. Helicobacter pylori-positive versus Helicobacter pylori-negative idiopathic peptic ulcers in children with their long-term outcomes. I Pediatr Gastroenterol Nutr 2009;48:299-305.

2. Deckelbaum RJ, Roy CC, Lussier-Lazaroff J, Morin CL. Peptic ulcer disease: a clinical study in 73 children. Can Med Assoc I 1974;111:225-8

3. Hua MC, Kong MS, Lai MW, Luo CC. Perforated peptic ulcer in children: a 20-year experience. I Pediatr Gastroenterol Nutr 2007; 45:71-4.

4. Azarow K, Kim P, Shandling B, Ein S. A 45-year experience with surgical treatment of peptic ulcer disease in children. I Pediatr Surg 1996;6:750-3.

5. Yıldız T, Ateş M, Karaaslan E. Peptic Ulcer Perforation in a Child: Case Report. Akademik acil tıp dergisi 2011:10;177-9.

6. Schwartz S, Edden Y, Orkin B, Erlichman M. Perforated peptic ulcer in an adolescent girl. Pediatr Emer Care 2012;28:709-11.

7. Lee NM, Yun SW, Chae SA, Yoo BH, Cha SJ, Kwak BK. Perforated duodenal ulcer presenting with massive hematochezia in a 30-month-old child. World I Gastroenterol 2009;15:4853-5.

8. Wang JY, Liu SB, Chen SY, Dobson A. Risk factors for peptic ulcer in Shanghai. Int J Epidemiol 1996;25:638-43.

9. García-González MA, Lanas A, Savelkoul PH, et al. Association of interleukin 1 gene family polymorphisms with duodenal ulcer disease. Clin Exp Immunol 2003;134:525-31.

10. Felix WR Jr, Stahlgren LH. Death by undiagnosed perforated peptic ulcer: analysis of 31 cases. Ann Surg 1973;177:344-51.

11. Wallstabe L, Veitt R, Körner T. Diagnosis of perforated gastric ulcers by ultrasound. Z Gastroenterol 2002;40:877-80.

12. Kim SH, Shin SS, leong YY, Heo SH, Kim JW, Kang HK. Gastrointestinal tract perforation: MDCT findings according to the perforation sites. Korean / Radiol 2009;10:63-70.

13. Wysocki A, Budzyński P, Kulawik J, Drożdż W. Changes in the localization of perforated peptic ulcer and its relation to gender and age of the patients throughout the last 45 years. World I Surg 2011;35:811-6.

14. Dakubo JC, Naaeder SB, Clegg-Lamptey IN. Gastro-duodenal peptic ulcer perforation. East Afr Med I 2009;86:100-9.

15. Critchley AC, Phillips AW, Bawa SM, Gallagher PV. Management of perforated peptic ulcer in a district general hospital. Ann R CollSurg Engl 2011;93:615-9. 